\title{
Depth- and time-dependent vertical strain rates at Siple Dome, Antarctica
}

\author{
Daniel H. ELSBERG, ${ }^{1}$ William D. HARRISON, ${ }^{1}$ Mark A. ZUMBERGE, ${ }^{2}$
} John L. MORACK, ${ }^{1}$ Erin C. PETTIT, ${ }^{3}$ Edward D. WADDINGTON ${ }^{3}$, Eric HUSMANN ${ }^{2}$

\author{
${ }^{1}$ Geophysical Institute, University of Alaska, 903 Koyokuk Drive, Fairbanks, Alaska 99775-7320, USA \\ E-mail: ftdhe@uaf.edu \\ ${ }^{2}$ Scripps Institution of Oceanography, University of California-San Diego, La Jolla, California 92093-0225, USA \\ ${ }^{3}$ Department of Earth and Space Sciences, University of Washington, Seattle, Washington 98195-1310, USA
}

\begin{abstract}
As part of a project to investigate the flow of ice at low effective stress, two independent strain-gauge systems were used to measure vertical strain rate as a function of depth and time at Siple Dome, Antarctica. The measurements were made from January 1998 until January 2002 at the ice divide and a site $7 \mathrm{~km}$ to the northeast on the flank. The strain-rate profiles place constraints on the rheology of ice at low stress, show the expected differences between divide and flank flow (with some structure due to firn compaction and probably ice stratigraphy), and suggest that the flow of the ice sheet has not changed much in the last $8.6 \mathrm{kyr}$. The strain rates show an unexpected time dependence on scales ranging from several months to hours, including discrete summer events at the divide. Time dependence in strain rate, water pressure, seismicity, velocity and possibly basal motion has been seen previously on the Siple Coast ice streams, but it is especially surprising on Siple Dome because the bed is cold.
\end{abstract}

\section{INTRODUCTION}

Ever since the mapping of several fast-flowing ice streams which carry large quantities of ice from the interior of the West Antarctic ice sheet to the Ross Sea, there has been interest in the ice-transport mechanisms of the region (e.g. Zumberge and others, 1969; Hughes, 1973; Rose, 1979). There is evidence that on time-scales of centuries or even years, the locations and velocities of some of the ice streams have varied (e.g. Alley and Whillans, 1991; Conway and others, 2002). One area that has not been overrun by ice streams in at least the last $10 \mathrm{kyr}$ is the current location (Fig. 1) of Siple Dome (Nereson and others, 1998). It spans $120 \mathrm{~km}$ across from Kamb Ice Stream (former Ice Stream C) to Bindschadler Ice Stream (former Ice Stream D) and reaches $620 \mathrm{~m}$ elevation at the summit (Raymond and others, 1995). This long-term stability led to the choice of Siple Dome as a site for acquisition of an ice core for paleoclimatic studies.

The logistical accessibility of Siple Dome associated with the coring project provided an opportunity to investigate a fundamental question: how does ice flow at low effective stress (Pettit and Waddington, 2003)? Low effective stress is characteristic of ice divides such as Siple Dome. This paper, together with an earlier one (Zumberge and others, 2002), reports on the observational part of a project to address this problem, the field measurement of vertical strain rate as a function of depth. The analysis of the measurements in terms of a flow law of ice which includes the low-stress behavior is given separately (Pettit, 2003). In addition, the data in this paper permit some interesting correlations to be made with the ice-core stratigraphy, and raise some basic questions about ice flow because of a time-dependent component in the strain rate.

Because the ice-flow pattern changes with distance from the divide, vertical strain rate was measured at two sites, one at the ice divide itself (where the flow is essentially vertical), and one on the flank (where the flow is more or less horizontal). The 'Divide' site was at $81^{\circ} 39.3^{\prime} \mathrm{S}, 148^{\circ} 49.3^{\prime} \mathrm{W}$,

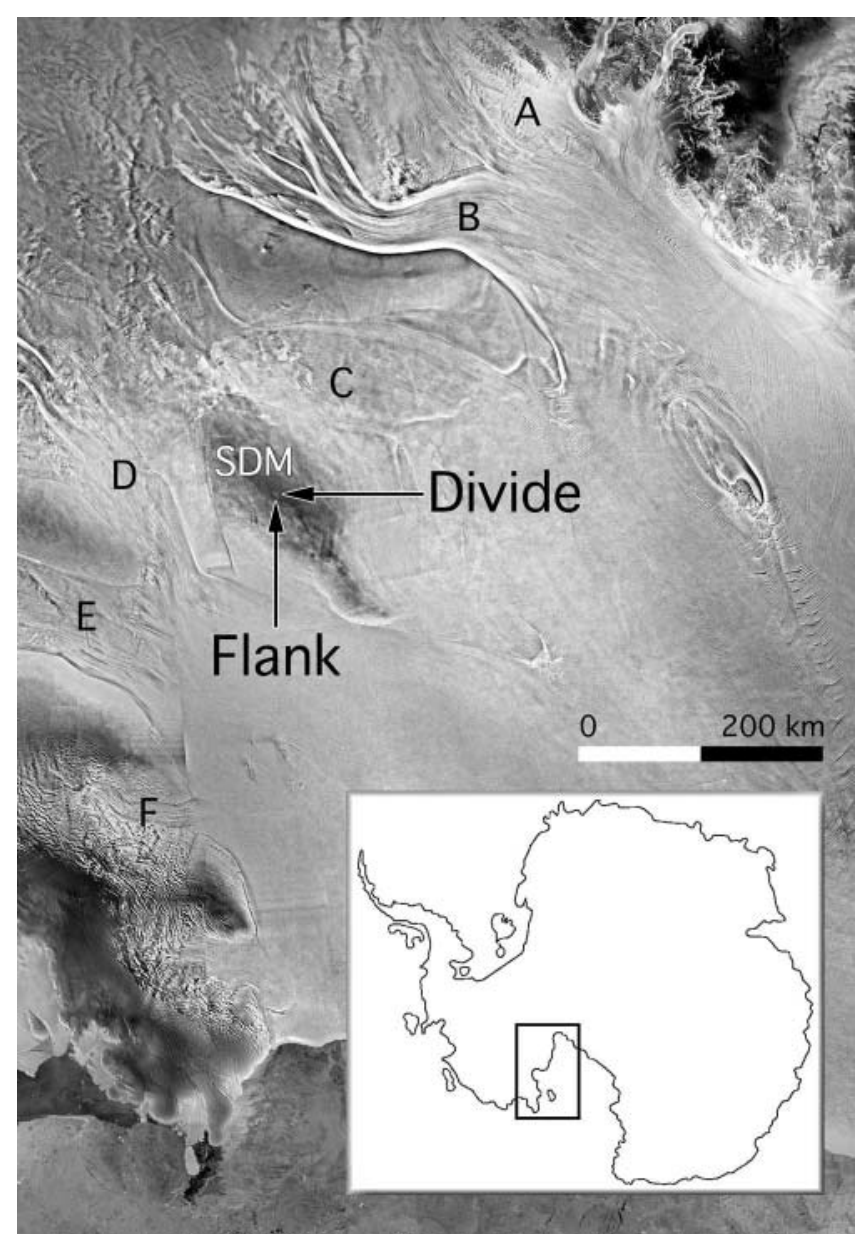

Fig. 1. Location map of the study area and the surrounding Siple Coast. Siple Dome is labelled SDM, and the six Siple Coast ice streams by their lettered variant names. Base image mosaic from the RADARSAT-1 Antarctic Mapping Project (RAMP). Antarctic Mapping Mission-1 (AMM-1) synthetic aperture radar image mosaic of Antarctica (Jezek and others, 2002). 


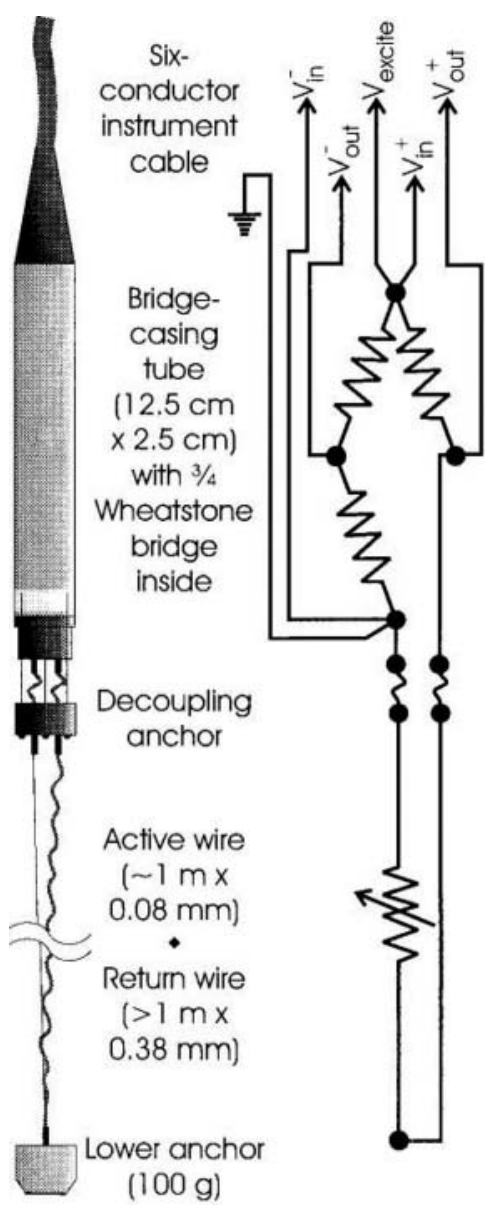

Fig. 2. A resistance-wire gauge. The dummy gauge (not pictured) incorporates the active wire into the bridge casing, and thus eliminates the decoupling and lower anchors, and the return wire.

approximately $500 \mathrm{~m}$ north of the deep ice-core site. The 'Flank' site was $81^{\circ} 35.7^{\prime} \mathrm{S}, 148^{\circ} 41.6^{\prime} \mathrm{W}, 7 \mathrm{~km}$ to the northeast. The ice is $1004 \mathrm{~m}$ thick at Divide and $980 \mathrm{~m}$ at Flank (Gow and Engelhardt, 2000). All depths are given as vertical distances below the surface; changes during the 4 year course of the observations are negligible compared to other uncertainties.

Because the measurement of small vertical strain rates is difficult, we used two complementary types of strain gauges. One was a fiber-optic system whose performance had been relatively well documented, and the other a resistance-wire system whose performance was not as well known, but which had the capability to make measurements over length and time-scales orders of magnitude shorter than the optical system. Here we focus on the resistance-wire measurements, but we also update the fiber-optic results (Zumberge and others, 2002) with an additional year of data. Both types of gauges were installed in deep boreholes at Siple Dome in December 1997 and January 1998. We returned approximately annually for 4 years to collect data and perform maintenance work. Day 1 is defined as 1 January 1998; the subsequent field visits were centered around days 376, 704, 1057 and 1463.

\section{INSTRUMENTATION}

\subsection{Resistance-wire system}

The resistance-wire system is a modified version (Elsberg, 2003) of that described by Harrison and others (1993), which measures strain rate by sensing the change in distance between two anchors frozen into the ice approximately $1 \mathrm{~m}$ apart. The system is a Wheatstone bridge, with three resistance wires coiled up inside a cylindrical bridge casing. A 'decoupling' anchor hangs by three fine threads approximately $5 \mathrm{~cm}$ below the bridge casing. The fourth or 'active' wire stretches from the decoupling anchor down to a lower anchor, with a thicker, loosely hanging 'return' wire completing the circuit (Fig. 2). Change in the spacing between the anchors causes a proportional change in the resistance of the active wire, which is sensed by the imbalance of the bridge. 'Dummy' gauges were also constructed to monitor the long-term stability of the gauges and data loggers. These have all four wires inside the casing to isolate them from the deforming ice.

The gauges were laboratory-tested over a period of 5 months at $-7^{\circ} \mathrm{C}$. This allowed gauges with excessive drift or sudden jumps in output to be identified and repaired. Gauge factors, which convert data logger output to strain, were measured for 14 gauges. The differences among individual gauges was so small that the average $(0.500 \pm 3 \%)$ was used for all. There was no temperature variation from -15 to $+20^{\circ} \mathrm{C}$. Three factors contribute to the uncertainty: the repeatability of the measurement on a single gauge, the variability of the gauge factors measured on multiple gauges, and systematic errors in the measurement method.

Thirteen active and two dummy gauges were installed at 11 depths at each site, each in its own hot-water-drilled hole. Holes were laid out in a grid with a spacing of approximately $2 \mathrm{~m}$. The gauges hung vertically in the holes without touching the walls or bottom. All the active gauges produced a wildly varying initial transient signal during freeze-in, which lasted up to 1 week. Four of the 26 active gauges failed without producing useful data, three at Divide and one at Flank.

Each of the eight Campbell Scientific 21X data loggers logged from one to four gauges year-round at intervals of $30-90 \mathrm{~min}$ and a resolution of 0.6 or $2 \mu \varepsilon\left(1 \mu \varepsilon=10^{-6}\right.$ strain). The loggers were in desiccated enclosures.

\subsection{Comparison of resistance-wire and fiber-optic systems}

The optical-fiber system and its application to vertical strain measurement at Siple Dome have been described by Zumberge and others (2002). Although this and the resistance-wire system operate on different physical principles, from a practical point of view only two things are different. The first is the 'gauge length', the distance over which strain is averaged by the strain measurement. This is 170 (or 180) $\mathrm{m}$ for the optical system, and $1 \mathrm{~m}$ for the resistance system. The second difference is the time resolution. The resistance system lends itself to unattended logging, and thus to high time resolution, while the optical system was read at yearly intervals by field personnel. The small gauge length of the resistance system makes it capable of relatively high spatial resolution, but it is much more sensitive to anchor-to-ice coupling and interaction that could affect a relatively large fraction of the gauge length. These interactions can be classified into steady-state and transient categories. In the first category, there is some localized but permanent flow distortion caused by the instrument casing and cable. In the second, there are transient effects associated with installation, such as those arising from stress concentration 
near the lower anchor when the holes freeze (from the top, where it is relatively cold, to the bottom). These affect the strain rates and take a long time to decay. Whatever these mechanisms, by affecting a relatively large fraction of the $1 \mathrm{~m}$ length of the active wires they make the resistance-wire gauges relatively sensitive to installation transients.

\section{RESULTS}

The absolute measurement of small vertical strain rates is a difficult task because of complications arising from the installation transients, real-time dependence in the strain rates, and certain instrumental effects. Moreover, the data obtained by the two strain systems must be reconciled. It is therefore necessary to carry out a careful analysis of these problems as the data are presented, using the control (provided by the dummy gauges) and the redundancy (pairs of gauges at several depths) which were designed into the measurement program. To do so is the purpose of this section. The goal is to produce the clearest possible picture (one from which instrumental and installation effects are removed) of the spatial and temporal dependence of the absolute value of the strain rate at the Divide and Flank sites.

\subsection{Long-term average strain rates}

\subsubsection{Resistance-wire data}

The data collected over 4 years from two gauges $(167 \mathrm{~m}$ and $514 \mathrm{~m}$ at Flank) are shown in Figure 3 as examples. In Figure $3 \mathrm{a}$ the initial strain is arbitrary (depending upon the initial imbalance of the bridge) and varies from gauge to gauge. The slope of the curves is the strain rate, the target of our measurements, but there is a complication because the slope is a function of time. This can be seen in the early part of the data in Figure 3a (particularly at the $514 \mathrm{~m}$ gauge), but it is more evident in Figure $3 b$, in which the linear trends have been removed. The annual average measured strain rates are shown in Figure $4 a$ and $b$.

The deeper Flank gauges have corrections for shear strain. Shear contributes to the length change measured by a gauge when it is not perpendicular to the shear plane, and it varies with time as the gauge is rotated. Pettit (2003, appendix C) describes how corrections for the effect were made with the help of a numerical model, and the difficulties in estimating their uncertainties. The magnitudes of the shear corrections made can be seen in Table 1; they appear to be important only for the deepest gauge at Flank.

All the data show some time dependence in addition to that caused by the shear effect. Some of it is real, as discussed below, but much of it is from the slowly dying installation transient. Removal of the transient is difficult because its detailed physics is not understood. We do know that the effect is most important over short gauge lengths (as discussed above), that it is extreme in its initial phases during freeze-in and subsequent temperature equilibration, that it can last for years (although it decreases with time), that usually it is in the direction which causes the nominal compressive strain rate to be too large, and that it varies from gauge to gauge. All except the first of these features are illustrated by Figures $3 a$ and $b$ and 4 . Notice, for example, the different duration of the transient for two Divide gauges at the same depths, 171 and 171a, in Figure 4a; it appears that they are converging on the time-scale of years.

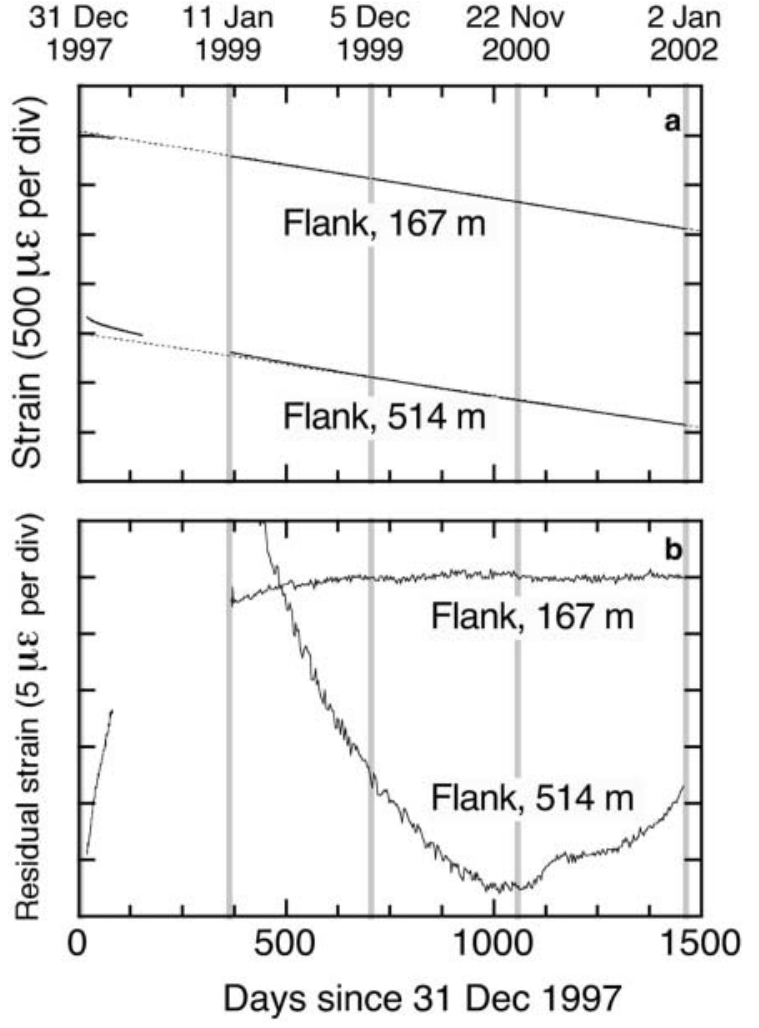

Fig. 3. (a) Examples of resistance-wire gauge records of strain. (b) The same records after removal of a linear trend. The median dates of the field visits are highlighted with gray bars.

Because of the unknown physics of the transient, and because in Figure $4 a$ and $b$ it can be seen that the strain rate tends to stabilize after 2 or 3 years, we took an average of the last 2 years as the best estimate of the undisturbed, long-term average strain rate. The uncertainty was taken to be the quadrature sum of the gauge factor uncertainty $(3 \%)$ and the change in annual strain rate between each of the last 2 years. Usually the gauge factor uncertainty dominated, but in a few cases the effect of the transient dominated and could have been underestimated. The results, corrected for shear strain, are plotted in Figure 5a. Table 1 shows the results with and without these corrections.

\subsubsection{Fiber-optic data}

The fiber-optic data were reduced using the approach described by Zumberge and others (2002), but with an extra year of data. The annual strain rates are summarized in Figure $4 \mathrm{c}$ and $\mathrm{d}$ and the 4 year average strain rates in Table 1 and Figure $5 \mathrm{~b}$ and $\mathrm{c}$. Like the resistance-wire data, they include corrections for shear strain at Flank. Careful inspection of Figure $4 c$ and $d$ shows a tendency for the magnitude of the annual strain rates to decrease during the 4 years, particularly over the two lowest depth intervals at Flank, but this effect is probably due to the difficulty of making accurate shear strain corrections.

\subsubsection{Comparison of fiber-optic and resistance- wire data}

Although the fiber-optic and resistance-wire strain systems give generally similar results for the long-term average strain rates, there are some differences which need to be discussed. To facilitate comparison, in Figure $5 \mathrm{~b}$ and $\mathrm{c}$ the 
Table 1. Long-term average strain rates as measured by the resistance-wire (averaged over years 3 and 4) and fiber-optic (averaged over all four years) gauges. The former are reported for each gauge, and as average rates over the same depth intervals as the optical fibers. $X^{\prime}$ 's indicate non-functioning gauges. Where relevant, these strain rates have been 'corrected' to remove the modeled effects of shear strain (on the deeper Flank gauges). The corrected rates are in bold; the uncorrected values follow in parentheses. The stated errors do not include the contribution from shear strain uncertainty. The best absolute values for the resistance-wire gauges are obtained by dividing by 1.12 and 1.16 at Divide and Flank, respectively (see text)

\begin{tabular}{|c|c|c|c|c|c|c|c|}
\hline \multirow[b]{2}{*}{$\begin{array}{l}\text { Depth } \\
\mathrm{m}\end{array}$} & \multicolumn{2}{|c|}{ Wires } & \multicolumn{3}{|c|}{ Wires } & \multicolumn{2}{|c|}{ Optical fibers } \\
\hline & $\begin{array}{l}\text { Strain rate } \\
\mu \varepsilon \mathrm{a}^{-1}\end{array}$ & $\begin{array}{l}\text { Uncertainty } \\
\mu \varepsilon \mathrm{a}^{-1}\end{array}$ & $\begin{array}{l}\text { Depth interval } \\
\mathrm{m}\end{array}$ & $\begin{array}{l}\text { Strain rate } \\
\mu \varepsilon \mathrm{a}^{-1}\end{array}$ & $\begin{array}{l}\text { Uncertainty } \\
\mu \varepsilon \mathrm{a}^{-1}\end{array}$ & $\begin{array}{l}\text { Strain rate } \\
\mu \varepsilon \mathrm{a}^{-1}\end{array}$ & $\begin{array}{l}\text { Uncertainty } \\
\mu \varepsilon \mathrm{a}^{-1}\end{array}$ \\
\hline \multicolumn{8}{|l|}{ Divide } \\
\hline 80 & -356 & 13 & $80.0-261.5$ & -245 & 5 & -217 & 3 \\
\hline 171 & -230 & 7 & & & & & \\
\hline $171 \mathrm{a}$ & -246 & 10 & & & & & \\
\hline 262 & $x$ & $x$ & $261.5-443.0$ & -176 & 3 & -171 & 7 \\
\hline 353 & -179 & 5 & & & & & \\
\hline 444 & -160 & 5 & $443.0-624.7$ & -137 & 4 & -106 & 9 \\
\hline 535 & -144 & 10 & & & & & \\
\hline 626 & -101 & 4 & $624.7-806.4$ & -80 & 4 & -59 & 7 \\
\hline 717 & $x$ & $x$ & & & & & \\
\hline $717 a$ & -99 & 10 & & & & & \\
\hline 798 & -18 & 1 & & & & & \\
\hline 899 & -3 & 1 & $806.4-985.0$ & -3 & 0 & -9 & 9 \\
\hline 944 & $x$ & $x$ & & & & & \\
\hline \multicolumn{8}{|l|}{ Flank } \\
\hline 80 & -414 & 13 & $80.0-253.5$ & -278 & 5 & -230 & 4 \\
\hline 167 & -247 & 7 & & & & & \\
\hline $167 a$ & -252 & 8 & & & & & \\
\hline 254 & -241 & 7 & $253.5-427.1$ & -236 & 5 & -221 & 7 \\
\hline 340 & -232 & 7 & & & & & \\
\hline 427 & -239 & 10 & & & & & \\
\hline 514 & -235 & 11 & $427.1-600.8$ & -233 & 5 & -203 & 5 \\
\hline 600 & -225 & 7 & & & & & \\
\hline 687 & $\mathbf{- 2 0 7}(-209)$ & 7 & $600.8-774.4$ & -186 & 4 & -142 & 7 \\
\hline $687 a$ & $\mathbf{- 2 1 4}(-216)$ & 7 & & & & & \\
\hline 774 & $\mathbf{- 9 8}(-96)$ & 9 & & & & & \\
\hline 861 & $\mathbf{- 1 2 8}(-101)$ & 4 & 774.4-948.1 & -108 & 3 & $-73(-64)$ & 9 \\
\hline 905 & $X$ & $X$ & & & & & \\
\hline
\end{tabular}

resistance-wire data are presented as averages over the same depth intervals as covered by the fiber-optic data (approximately 170 or $180 \mathrm{~m}$ effective gauge lengths). To obtain these averages, a smooth cubic-spline curve was fitted to the resistance-wire data, constrained to be zero at the bed, integrated over the appropriate depth interval, and divided by the interval length to produce the appropriate averages. We assumed the uncertainty in the interval averages to be dominated by the uncertainties in the three points involved, thereby neglecting the imperfections of the splines as interpolation functions between the data points in the case of a complex strain-rate field. The shallowest interval averages (80-261.5 $\mathrm{m}$ at Divide and $80-253.5 \mathrm{~m}$ at Flank) are biased toward a more negative value because the splines do not account for the large strain-rate gradient at $80 \mathrm{~m}$, but the overall result is not affected much.

Comparing the averaged resistance-wire and fiber-optic data, one finds that all but one of the former points fall to the left of the corresponding fiber-optic points. This indicates a real systematic offset between the data from the two systems. A one-parameter best-fit line to the eight deepest resistancewire gauges indicates a nominal strain rate on average $15 \%$ larger in magnitude than measured by the optical-fiber gauges $(12 \%$ at Divide and $16 \%$ at Flank). All the resistancewire data should be normalized using these numbers to produce the best absolute accuracy, because we expect the fiber-optic gauges to have the higher absolute accuracy due to their relative insensitivity to end effects.

The offset between the two sets of gauges seems to be the result of uncertainty in where the upper portions of the resistance gauges were coupled to the ice. Their calibration (represented by the gauge factor) assumes that each of the two anchors (Fig. 2) moves at the same velocity as the adjacent ice, as depicted by the lefthand gauge in Figure 6 . This is valid if the ice does not communicate any of the motion of the bridge casing to the decoupling anchor. If, as with the righthand gauge in Figure 6 , the ice located between the bridge casing and the decoupling anchor acts as a rigid body, then the entire upper assembly moves as one piece. In this case, it is the difference in velocities between the ice somewhere above the decoupling anchor and the ice at the depth of the lower anchor that causes the measured strain. Hence there is an increase in the actual gauge length which is not accounted for in the gauge-factor measurements. The ruler scale in Figure 6 shows that the amount of this increase in the gauge length is $5-25 \mathrm{~cm}$, depending on where the upper gauge body was effectively coupled to the ice. This would cause a corresponding $5-25 \%$ systematic offset in the measured strain rates, as we observed between the two gauge types. A significantly larger distance between 


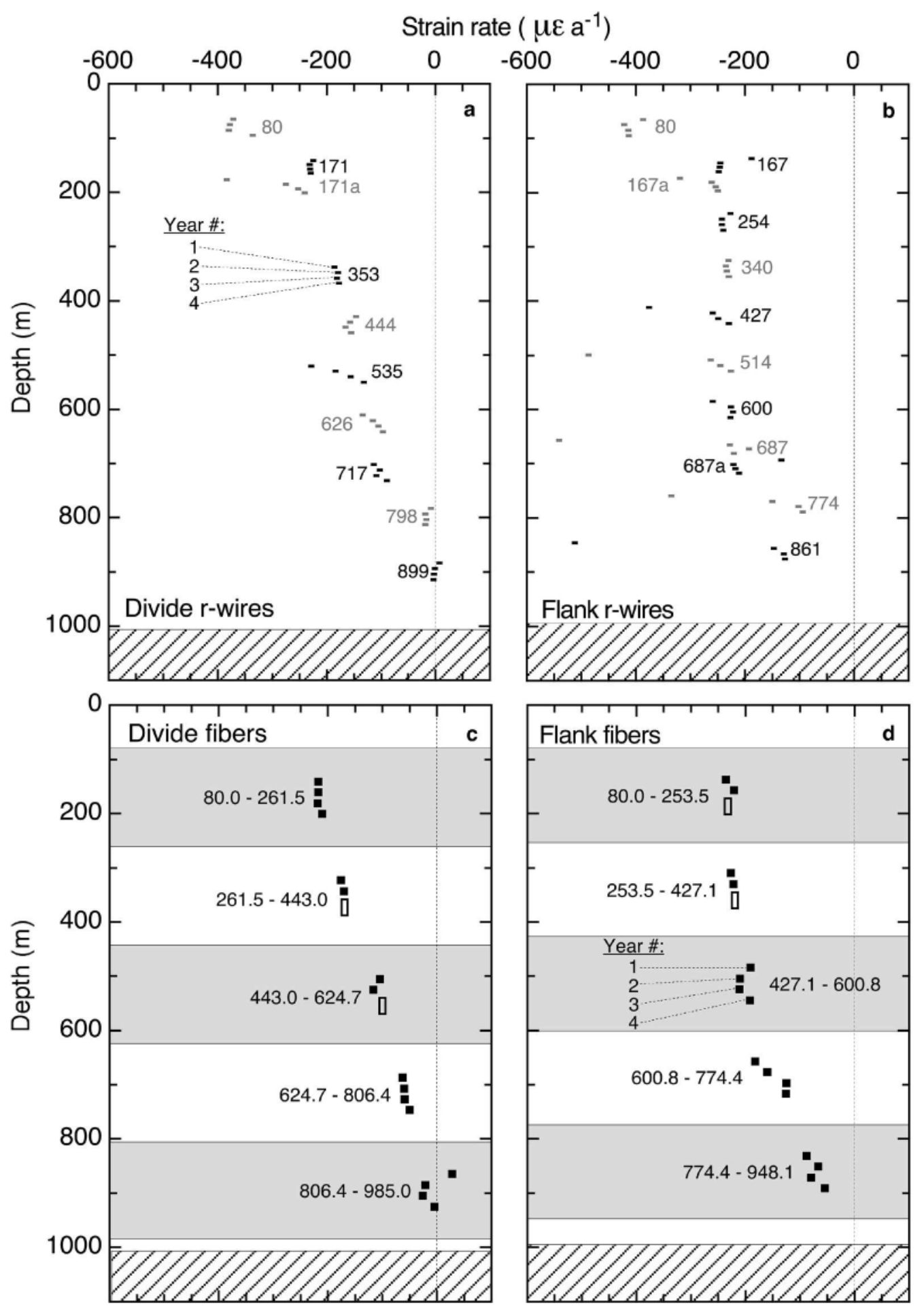

Fig. 4. One-year average resistance-wire strain rates at Divide (a) and Flank (b), and the fiber-optic strain rates at Divide (c) and Flank (d). The data are grouped together by depth, with each 4 years of data plotted as labeled for the $353 \mathrm{~m}$ Divide gauge. In (c) and (d) the four open boxes represent 2 year averages, due to outliers in the data. The diagonal hatches start at the depth of the bed. The alternating white and gray bands in (c) and (d) highlight the depth intervals sampled by the fibers.

the decoupling anchor and bridge casing would remedy the problem.

\subsection{Spatial variability}

In addition to the systematic offset between the two gauge types, the averages from the normalized resistance gauges scatter about the best fit to the optical gauges by an rms value of $17 \mu \varepsilon \mathrm{a}^{-1}$ (14 at Divide and 19 at Flank). We need to consider whether this represents real conditions or is due to some measurement effect yet to be identified. In the latter case, the most obvious possibility is that the installation transient, whose strength varies from gauge to gauge, is larger than we think and is not properly accounted for. Another possibility is variability from gauge to gauge in the effective coupling point between the ice and the instrument case. (Like the systematic offset, this would be due to ineffectiveness of the decoupling anchor.) Effects such as these tend to generate artificial spatial structure in the strain-rate field. 


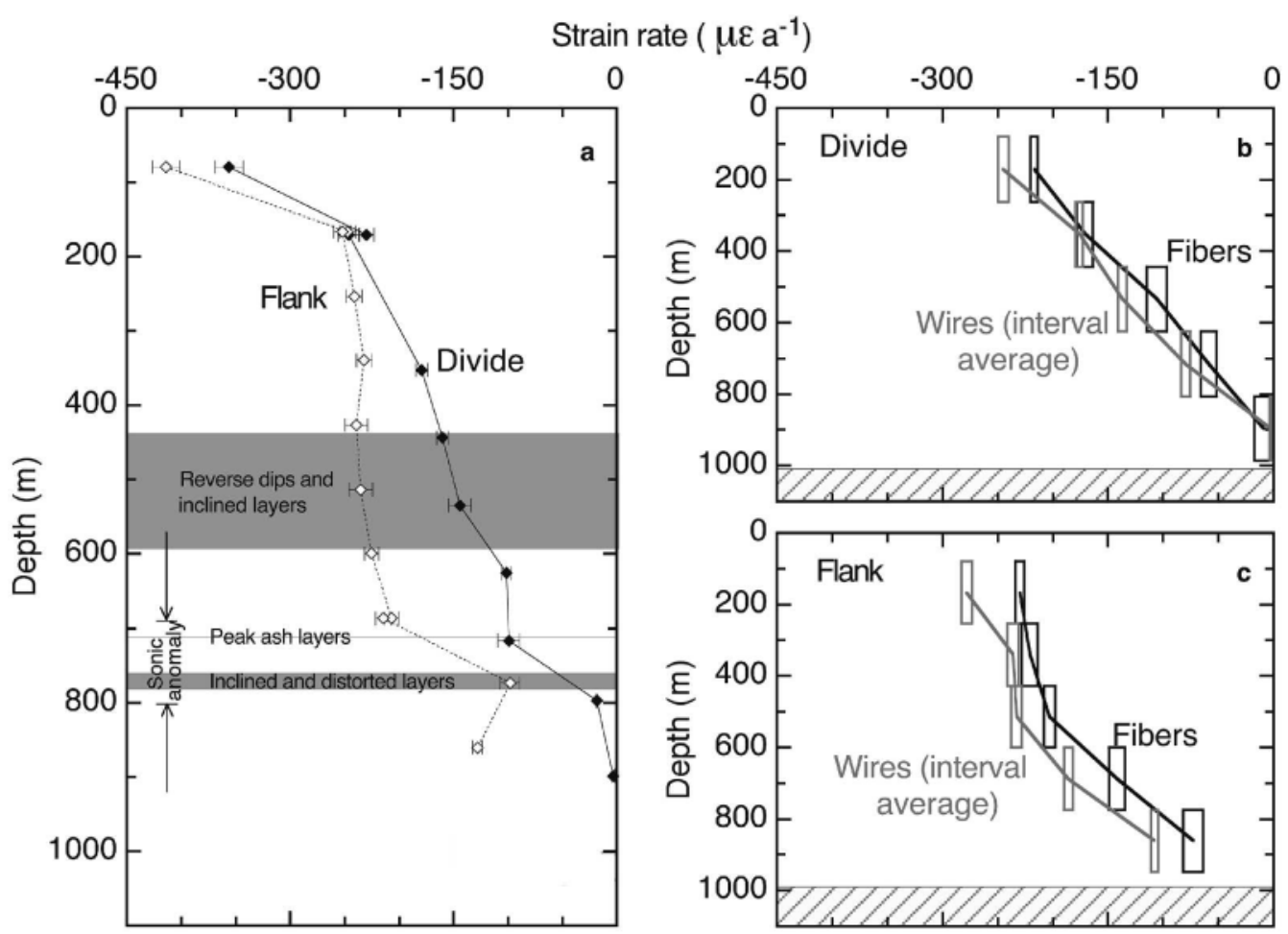

Fig. 5. (a) Long-term average strain rate as a function of depth as measured by the resistance wires. (b, c) These data are given as interval averages at Divide (b) and Flank (c) for comparison with the fiber-optic data. The diagonal hatches start at the depth of the bed. The rectangles at each data point represent the depth intervals (height) and strain uncertainties (width) reported in Table 1. Stratigraphic information is cited in the text.

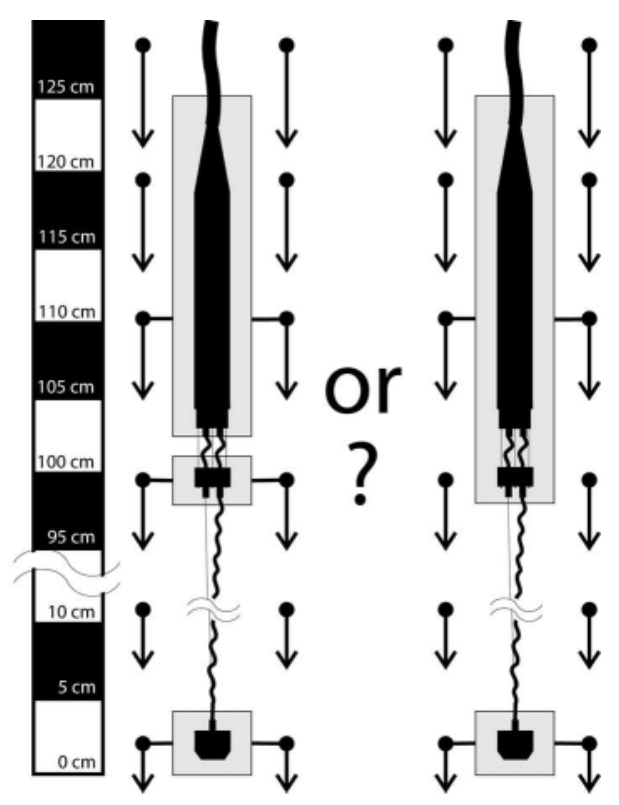

Fig. 6. Graphic showing the uncertainty in how the upper resistance-wire gauge assembly is coupled to the ice. The decoupling anchor in the example on the left is not influenced by the downward motion of the bridge casing; thus the gauge length is $100 \mathrm{~cm}$. In this case, the decoupling anchor and the casing have separate, independent effective coupling points. The decoupling anchor on the right moves as a single body with the bridge casing due to rigid ice between them; thus the gauge length is $110 \mathrm{~cm}$. The actual gauge length depends upon the rigidity of the ice above the decoupling anchor and the effective coupling point of the gauge body to the ice. A systematic uncertainty of $5-25 \%$ in the gauge factor is expected.
The redundancy provided by the three pairs of duplicate gauges at the same depths sheds some light on this question. The mean difference between the corresponding members of the pairs is $9 \mu \varepsilon \mathrm{a}^{-1}$ (calculated from Table 1), essentially all of which can be understood in terms of uncertainty in the gauge factor, or in one case $(171 \mathrm{~m}$ at Divide) by our simplistic handling of the installation transient. In these cases, at least, the different gauges gave consistent readings within the $9 \mu \varepsilon \mathrm{a}^{-1}$ uncertainty. Thus no unexpected instrumental effect is indicated which would account for the $17 \mu \varepsilon \mathrm{a}^{-1}$ scatter between the optical and normalized resistance data.

When normalizing the resistance to the optical data, one should realize that the optical system produces a direct average, while the limited sampling of the resistance system together with the spline interpolation produces a different result. The difference would be small if the strain-rate field were smoothly varying. Thus the most reasonable explanation for the scatter is real spatial structure in the strain-rate field. This is most obvious at $774 \mathrm{~m}$ at Flank, and possibly at $717 \mathrm{~m}$ at Divide (Fig. 5a); these points do not lie on the smooth curves which could be sketched through the data for the two sites in Figure 5a.

\subsection{Temporal variability}

An interesting feature of the data is the time dependence of the strain rate, in addition to that accounted for by the installation transient. This time dependence is best displayed by subtracting the quadratic trend for each active gauge. This removes both the average strain rate and any real secular changes on the scale of a few years, but it should give a reasonable representation of the time dependence on shorter time-scales, from the multi-month scale down to our 


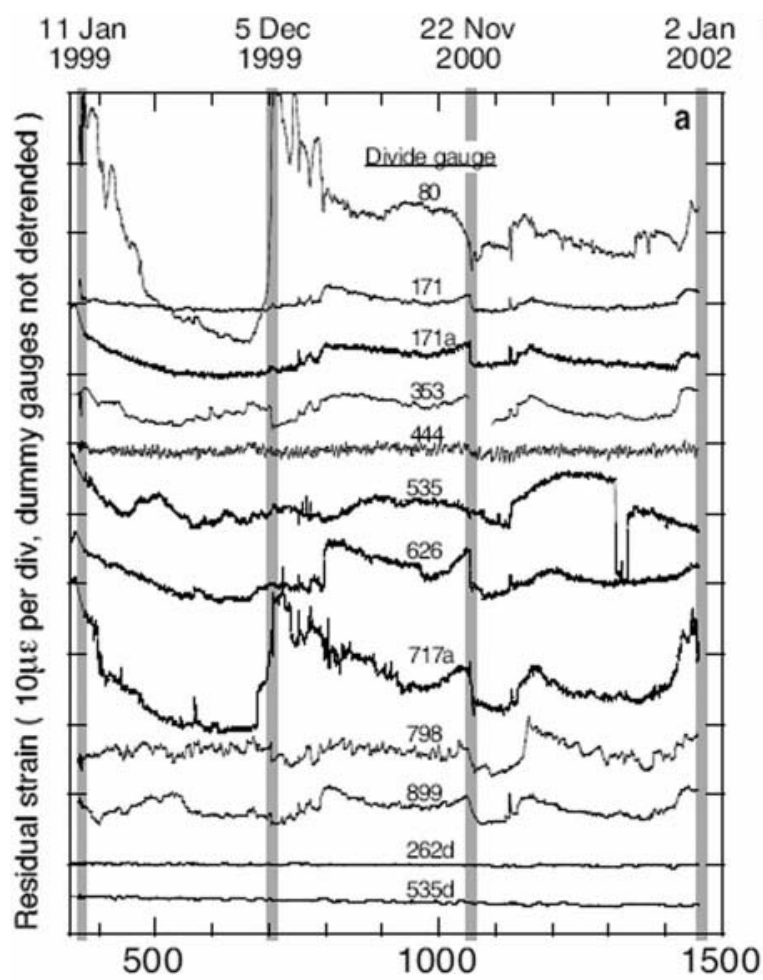

\begin{tabular}{llll}
11 Jan & $5 \mathrm{Dec}$ & $22 \mathrm{Nov}$ & $2 \mathrm{Jan}$ \\
1999 & 1999 & 2000 & 2002 \\
\hline
\end{tabular}

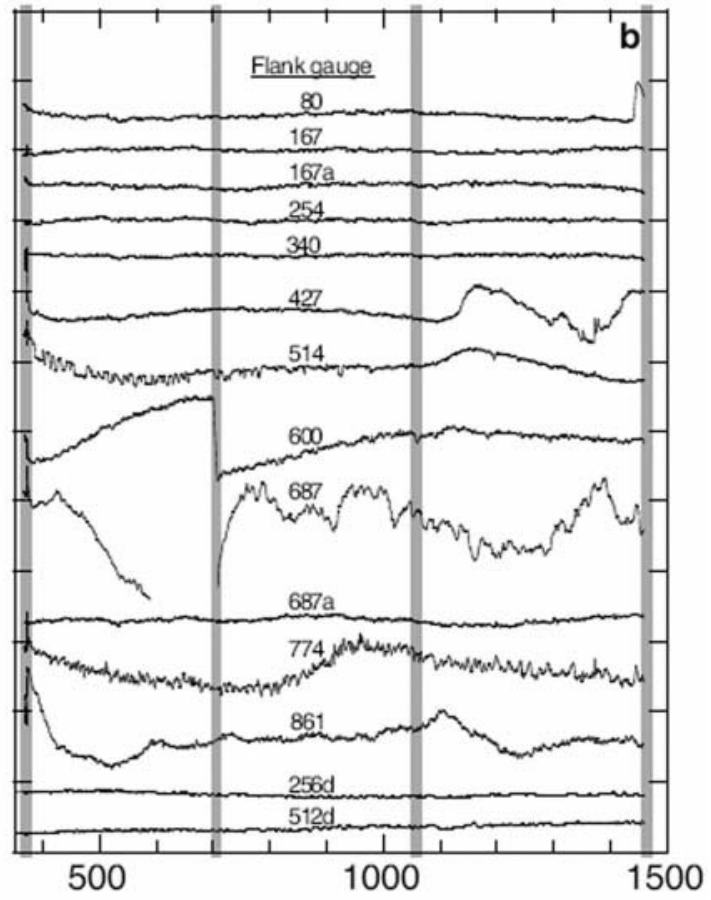

Days since 31 Dec. 1997

Fig. 7. Resistance-wire gauge records during years 2-4 at (a) Divide and (b) Flank after detrending by subtraction of the least-squares quadratic fits; the dummy gauge records (indicated by ' $d$ ') have not been detrended. The median dates of the field visits are noted and highlighted with gray bars.

temporal resolution of 1 or 2 hours. The result from years $2-4$ is shown in Figure 7; in Figure 8 expanded scales show the structure of certain interesting events. The plots do not show the data from year 1, which were heavily distorted by the installation transient.

The credibility of this time dependence needs to be considered carefully. On the positive side, the most important piece of evidence is the behavior of the four dummy gauges, whose purpose was to monitor system performance. The output from the dummy gauges is shown near the bottoms of Figure $7 a$ and $b$, and is identified by the suffix ' $d$ ' added to the gauge depth. The data from these gauges, unlike the active ones, are unaltered; no trends are subtracted. Nevertheless the output is constant at the level of 1 or $2 \mu \varepsilon \mathrm{a}^{-1}$ which is the data logger resolution. This suggests (but does not prove) that the system performance is ideal in the sense that the system accuracy (except for uncertainty in the gauge factor) is determined by the data logger resolution. In this ideal case, all the time variability exceeding the logger resolution would be real.

This conclusion tends to be supported by a second piece of evidence, the behavior of the three pairs of gauges at the same depth. These are the pairs $(171,171 \mathrm{a}, 2 \mathrm{~m}$ apart) at Divide, and (167, 167a, $6 \mathrm{~m}$ apart and 687, 687a, $7 \mathrm{~m}$ apart) at Flank, each member of which was connected to a different logger. The first two pairs show almost identical behavior (Fig. 7), at least after year 1 (recall that only years 2 to 4 are plotted), when it appears that the major part of the installation transient has decayed or is removed by detrending. However, the third pair behaved differently, which could be due to some unidentified instrumental effect, spatial inhomogeneity in the strain-rate field, or both.
The final piece of evidence supporting the reality of the time dependence is its similarity at most depths at Divide as recorded on four different data loggers, especially in the last year (Fig. 7). This is difficult to account for by an instrumental effect.

Despite these three positive indications that the time dependence is real, there does seem to be some instrumental effect in addition. The vertical shaded bars in Figure 7 represent the time intervals during which personnel were in the field digging out the logger enclosures, downloading logger memory modules, performing battery maintenance, and so on. During these periods, offsets can be seen in the strain at several gauges (especially at Divide) which are likely to be due to the associated disturbance. The problem is that none of these is recorded on the dummy gauges, which indicates that the dummies are not $100 \%$ indicative of system performance. At Flank (Fig. 7) there is only a single offset event (at $600 \mathrm{~m}$ in December 1999), and one can imagine, for example, that the wires to this one gauge were somehow disturbed at the data logger during maintenance but those to the two dummies were not. At Divide, however, there are offsets on so many gauges (particularly in November 2000) that it seems statistically unlikely that they would not occur on the dummies as well. The $444 \mathrm{~m}$ gauge stands out in that it shows neither offsets nor coherent patterns of time dependence.

Thus there is some instrumental effect which we do not understand. Several possibilities have been explored, but nothing was found that could be responsible. None of the time variation or offset events is correlated with battery voltage, which was logged along with strain. Neither was there any apparent correlation between the exact timing of 

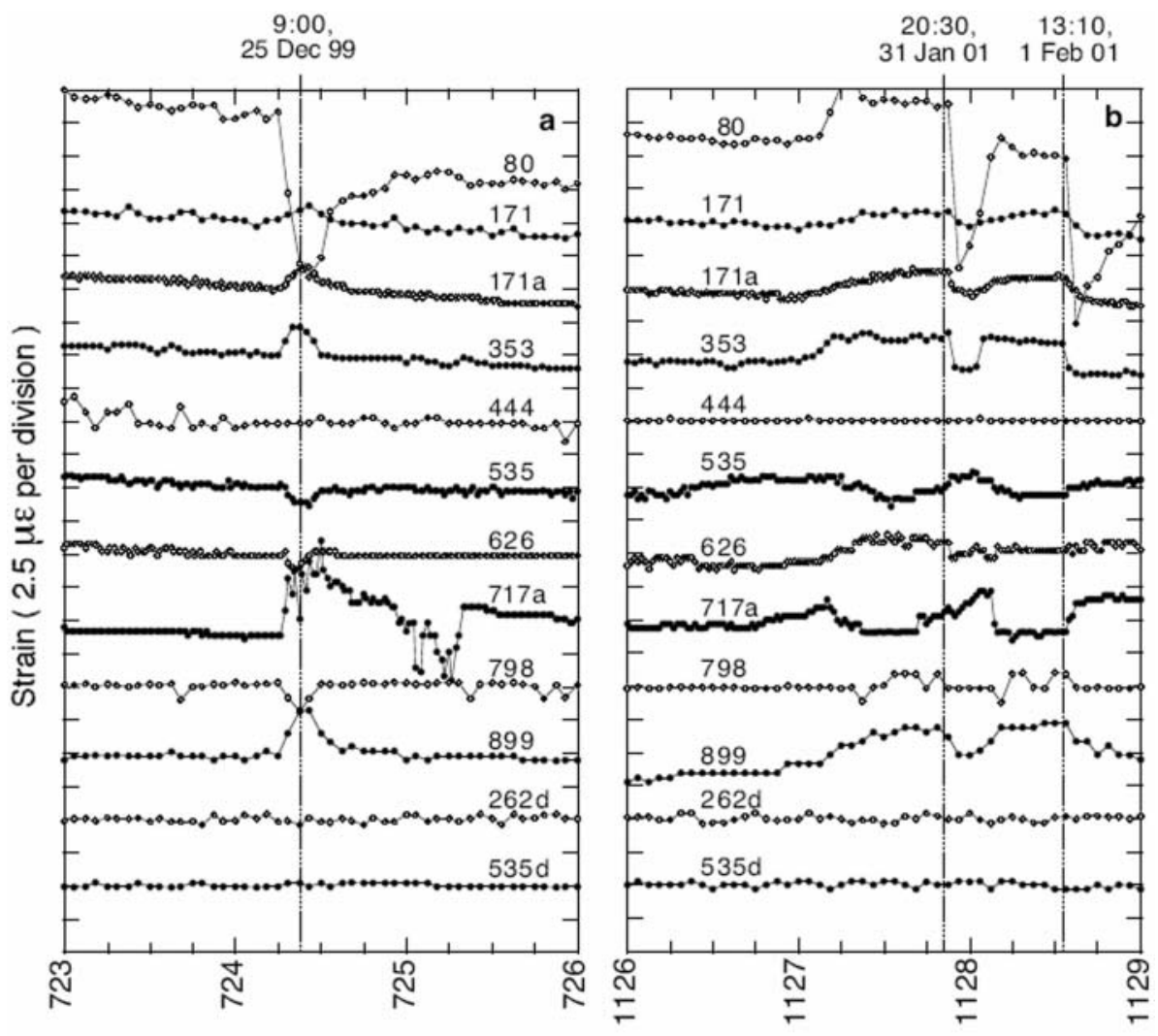

Days since 31 Dec. 1997

Fig. 8. Discrete strain events at Divide. One of these events occurred on day 724 (25 December 1999) (a) and two on days 1127 and 1128 (31 January and 1 February 2001) (b). The times above the figure and the gray bars aid in comparing the timing of the events.

the events and the timing of changes in temperature (also logged). Finally, it is unlikely that the short-period events such as those shown in Figure 8 are associated with the presence of Siple Dome camp and drilling site, which were closed when the two events of year 4 occurred.

Thus the evidence as a whole indicates that most of the time dependence is real, although there is some instrumental effect. It could negate some of the details of the time variation discussed below, but not its general structure.

\section{DISCUSSION OF THE RESULTS}

The previous section was devoted to presenting the data and removing effects which are spurious or mask the time variability. We are now in a position to present a qualitative description of the main features of the resulting strain-rate field.

\subsection{Spatial variability}

The difference in flow regimes at the two sites is roughly as expected (e.g. Raymond, 1983; Zumberge and others, 2002). Divide shows almost linear variation of strain rate with depth below the firn, while Flank, $7 \mathrm{~km}$ distant, shows more curvature, with the magnitude of the rates larger than at similar depths at Divide (Fig. 5). At both sites the strain rates are seen to be relatively large at $80 \mathrm{~m}$, because firn compaction is still active there. There is a difference in that the strain rate at $80 \mathrm{~m}$ is larger in magnitude at Flank. This could arise from the greater accumulation rate there (Nereson and others, 2000), but there is also a difference in horizontal strain rate which complicates the comparison of compaction rates. Firn compaction has also been studied at Divide by more detailed strain measurements using different methods, and by measurements of density in shallow firn cores (Lamorey, 2003; Hawley and others, 2004).

There is also structure in the variability of the strain field with depth as noted in the previous section, most notably at $774 \mathrm{~m}$ depth at Flank and possibly at $717 \mathrm{~m}$ at Divide. One would expect some structure because of complexities in the mechanical properties of ice as implied by the stratigraphy of the Siple Dome core. The most prominent stratigraphic anomaly (Figs 5a and 9) is the high sonic velocity from about 690 to about $800 \mathrm{~m}$ (personal communication from G. Lamorey, 2003), which indicates a strong vertical fabric and consequent rigidity of the ice to vertical strain. There are many volcanic ash and dust layers in this depth range, peaking at 711-713 m (Gow and Meese, 2003), which is near the depth of the $717 \mathrm{~m}$ Divide gauge and which may have some effect on vertical strain, possibly softening the ice as opposed to the hardening induced by the strong fabric. However, the correlation between strain rate and stratigraphy is indistinct, perhaps because of the large vertical spacing of the gauges, or even because the stratigraphy is different at our sites, approximately 0.5 and $7 \mathrm{~km}$ distant from the core hole.

There may well be more structure in the behavior of the strain rate with depth than is revealed by our $90 \mathrm{~m}$ vertical gauge spacing. The smallest separation that we have is the few horizontal meters between the three pairs of gauges, $171 \mathrm{~m}$ at Divide and 167 and $687 \mathrm{~m}$ at Flank. The first two pairs do not show any significant difference. However, the 
members of the third show the same long-term average but a different detailed time dependence. This could indicate inhomogeneity in the strain field on the scale of a few meters, but the evidence is not convincing in view of the instrumental effects discussed above.

\subsection{Time dependence on the multi-month scale}

Figures 7 and 8 show that the time dependence of the vertical strain rate varies on scales from several months to days or hours, with a characteristic amplitude on the order of $10 \mu \varepsilon$. This amplitude is usually more than an order of magnitude less than the strain accumulated in 1 year, except at the deeper Divide gauges where the two are comparable and the time variability thus complicates the problem of determining long-term averages.

The most impressive feature of the multi-month variability is the strong similarity of the strain rates at different depths at Divide, except at 444 and $535 \mathrm{~m}$, the former of which is conspicuously quiescent (Fig. 7a). In contrast, at Flank the correlation is weak, and the shallower gauges show little time dependence except for the feature at $80 \mathrm{~m}$ near the end of the record (Fig. 7b). The curious feature at $600 \mathrm{~m}$ at Flank in December 1999 is thought to be an instrumental effect, as discussed above.

\subsection{Discrete strain events at Divide}

Several prominent discrete strain events occurred at Divide. The six that are the most interesting, because they were evident at most depths, occurred during the third and fourth austral summers on days 724, 737, 738, 754, 1127 and 1128. (Because the strain readings returned to pre-event levels between the day 737 and 738 events, we refer to them as separate events. The same is true of the day 1127 and 1128 events.) Figure 8 shows several examples. The events, even more than the multi-month variability, were well correlated at different depths. Notably, however, the gauge at $444 \mathrm{~m}$ did not record either the discrete events or the multi-month variability. This type of event occurred only in summer but had no apparent correlation with any of the meteorological variables recorded at Simple Dome and archived by the Antarctic automatic weather stations (http://uwamrc.ssec.wisc.edu/aws/).

During each event the strain perturbation lasted 6-24 hours and the timing was coincident on all gauges to within $90 \mathrm{~min}$, the usual time resolution of the data loggers. Except for the $80 \mathrm{~m}$ gauges, where firn compaction may be a complicating factor, the strain during the events tends to be recoverable, in the sense that by the end of the event the strain has returned to its previous value. Plots similar to Figure 8 were used to estimate the amplitude of each strain event at each depth, the amplitude being defined as the maximum strain deviation from a line connecting the data points immediately before and after the event. The strain signal at $717 \mathrm{~m}$ in Figure $8 \mathrm{a}$ is more complex than at the other depths. As was typical during each of the first four events (days 724-754), the $717 \mathrm{~m}$ signal lasted longer than the others, and exhibited a positive change in strain followed by a negative change. The initial positive change was used to characterize the amplitude.

When the amplitudes for all six events are plotted together (Fig. 9), a pattern with depth is revealed that is almost the same for each event from $171 \mathrm{~m}$ down to $535 \mathrm{~m}$. All the amplitude curves cross from positive to negative strains at $444 \mathrm{~m}$; this gauge appears to be positioned at or

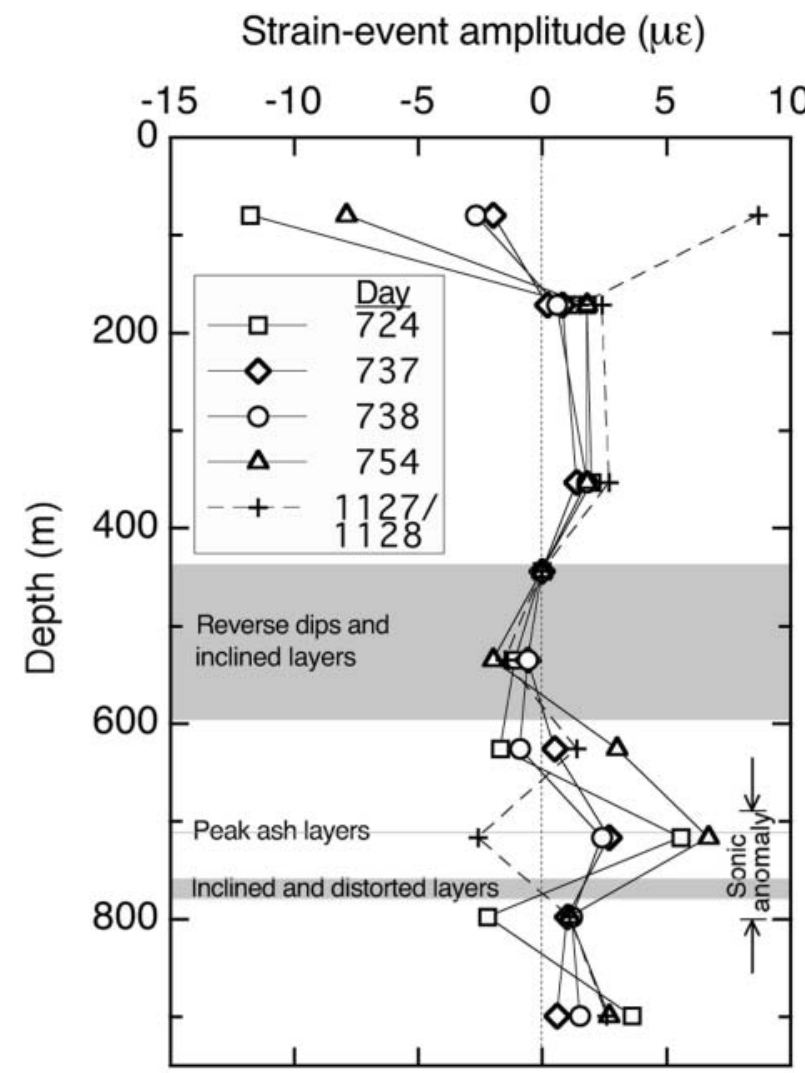

Fig. 9. Calculated amplitudes of discrete strain events at Divide. Those in 1999 and 2000 are plotted with solid lines. The two events in 2001 (days 1127 and 1128) are plotted as one set of points because the amplitudes were nearly identical; a dashed line connects these points because they differed from the earlier events. Strategraphic data from Gow and Meese (2003).

near a node where neither the discrete events nor the multimonth variability had any measurable effect. Below $535 \mathrm{~m}$ the amplitude patterns are less consistent among the different events, but not entirely incoherent, especially during the first four events (solid lines in Fig. 9). Something changed between the events occurring in 1999/2000 (year 3) and those in 2001 (year 4). During the two events in 2001, the amplitudes at $717 \mathrm{~m}$ changed sign and the signal was not anomalous relative to that at other depths.

There may be a weak but slightly more convincing correlation with the Siple Dome core stratigraphy than there was with the long-term average strain rates. At $717 \mathrm{~m}$, the large range of amplitudes (Fig. 9) and the anomalous signals seen during the first four strain events (e.g. Fig 8a) suggest that there is something special about the properties of the ice there. This is the range of the ash layers in the Siple Dome core, noted above. It is also noteworthy that the 444 gauge, which showed neither the multi-month variability nor the discrete events, is near a transition from simple to complex stratigraphy.

\subsection{Comparison with past strain rates at Divide}

A reliable age-depth relationship at Divide has been determined by Taylor and others (2003) from the Siple Dome core to a $514 \mathrm{~m}$ depth, where the age is about $8.6 \mathrm{kyr}$. This provides a basis for comparison of past and present vertical strain rates. Because of the large spacing of the resistance gauges, we used the fiber-optic data to compute 
an age-depth relationship. Steady state was assumed. The result is that the ages calculated from present strain rates are the same as those measured on the core within the uncertainty limits on the strain-derived ages. Thus changes in strain rate over the last $8.6 \mathrm{kyr}$ seem to have been small, less than roughly $10 \%$. More discussion is given by Nereson and others (1996), Elsberg (2003) and Pettit (2003).

\section{SUMMARY}

The measurement of vertical strain as a function of depth at Siple Dome was carried out as the observational part of a project to study the rheology of ice at the low effective stresses which exist at an ice divide. Two different reconcilable methods, each with its own advantages, were used. The results show the expected differences in flow at divide and flank sites, upon which is superimposed some vertical variability associated with the effects of firn compaction, and probably with ice stratigraphy. Taken together with the known age-depth relationship, the data also indicate that changes in the flow of the ice sheet near the Siple Dome divide have been small during the last 8.6 kyr.

Pettit (2003) gives an account of the interpretation of the measured long-term average vertical strain rates in terms of a 'cross-over' stress defining the transition from non-linear to linear rheology; its value is about $22 \mathrm{kPa}$. In fact, the Pettit analysis was a comprehensive one which considered not only vertical strain rate, but also temperature, surface velocity and, most importantly, anisotropy of the ice as inferred from the sonic velocity log. The same model was used to correct for the effects of shear strain on the vertical strain measurements.

The long-term average vertical strain rates place significant constraints on the rheology of flow at low effective stress, which was the purpose of the measurements. The variability of the strain rates, observed on time-scales ranging from months to hours, was a surprise. This variability is quite different at the Divide and Flank sites, possibly because it is superimposed upon different flow regimes.

Initially, a time-dependent component in the flow might have been expected because it seems to be common in the ice streams near Siple Dome (Fig. 1); it has been found in vertical strain rate (Harrison and others, 1993), seismicity (Harrison and others, 1993; Anandakrishnan and Alley, 1997), basal water pressure (Engelhardt and Kamb, 1997; Kamb, 2001), margin locations (e.g. Bindschadler and Vornberger, 1998; Harrison and others, 1998; Echelmeyer and Harrison, 1999), surface velocity (Bindschadler and others, 2003) and possibly basal motion (Engelhardt and Kamb, 1998). At least some of these effects can be associated with the behavior of basal water, but at Siple Dome the bed is cold. The occurrence of liquid water at the measured temperature of $-2.54^{\circ} \mathrm{C}$ (Engelhardt, 2004) seems unlikely, even when taking account of the effect of pressure and dissolved air on the equilibrium temperature (e.g. Harrison, 1975). This is probably the case over a large surrounding region, because radio-echo sounding (Gades and others, 2000) suggests that the properties of the bed are homogeneous across Siple Dome. The nearest temperate ice could well be under Bindschadler Ice Stream, about $55 \mathrm{~km}$ distant. The obvious unanswered question is why the time dependence occurs, and the relative importance of external forcing vs internal processes in causing it.

\section{ACKNOWLEDGEMENTS}

We are grateful to $\mathrm{H}$. Engelhardt and the California Institue of Technology hot-water drilling team who worked round the clock to provide us with open holes for the gauges, to C. Trabant who worked extensively on prototype resistancewire gauge testing and design improvements, and to the University of Alaska Geophysical Institute machine and electronics shops, where the resistance gauges were built. H. Englehardt and G. Lamorey provided important unpublished data. The work benefited from the comments of K. Echelmeyer, T.H. Jacka, P. Layer, C. Lingle, J. Reynolds and C. Raymond. Major improvements to the paper resulted from the comments of K. Cuffey, two anonymous reviewers, and R. Bindschadler, Scientific Editor. Funding was from the US National Science Foundation, OPP grants 9220199, 9615502, 9515454 and 9615417.

\section{REFERENCES}

Alley, R.B. and I.M. Whillans. 1991. Changes in the West Antarctic ice sheet. Science, 254(5034), 959-963.

Anandakrishnan, S. and R.B. Alley. 1997. Tidal forcing of basal seismicity of Ice Stream C, West Antarctica, observed far inland. J. Geophys. Res., 102(B7), 15,183-15,196.

Bindschadler, R. and P. Vornberger. 1998. Changes in the West Antarctic ice sheet since 1963 from declassified satellite photography. Science, 279(5351), 689-692.

Bindschadler, R.A., P.L. Vornberger, M.A. King and L. Padman. 2003. Tidally driven stick-slip motion in the mouth of Whillans Ice Stream, Antarctica. Ann. Glaciol., 36, 263-272.

Conway, H., G. Catania, C. Raymond, T. Scambos, H. Engelhardt and A. Gades. 2002. Switch of flow direction in an Antarctic ice stream. Nature, 419(6906), 465-467.

Echelmeyer, K.A. and W.D. Harrison. 1999. Ongoing margin migration of Ice Stream B, Antarctica. J. Glaciol., 45(150), 361-369.

Elsberg, D.H. 2003. Variations in ice flow and glaciers over time and space. (PhD thesis, University of Alaska Fairbanks.)

Engelhardt, H. 2004. Ice temperature and high geothermal flux at Siple Dome, West Antarctica, from borehole measurements. J. Glaciol., 50(169), 251-256.

Engelhardt, H. and B. Kamb. 1997. Basal hydraulic system of a West Antarctic ice stream: constraints from borehole observations. J. Glaciol., 43(144), 207-230.

Gades, A.M., C.F. Raymond, H. Conway and R.W. Jacobel. 2000. Bed properties of Siple Dome and adjacent ice streams, West Antarctica, inferred from radio-echo sounding measurements. J. Glaciol., 46(152), 88-94.

Gow, A.J. and H. Engelhardt. 2000. Preliminary analysis of ice cores from Siple Dome, West Antarctica. In Hondoh, T., ed. Physics of ice core records. Sapporo, Hokkaido University Press, 63-82.

Gow, A.J. and D.A. Meese. 2003. Physical and structural properties of the Siple Dome ice cores. Boulder, CO, National Snow and Ice Data Center. (Digital media.)

Harrison, W.D. 1975. Temperature measurements in a temperate glacier. J. Glaciol., 14(70), 23-30.

Harrison, W.D., K.A. Echelmeyer and H. Engelhardt. 1993. Shortperiod observations of speed, strain and seismicity on Ice Stream B, Antarctica. J. Glaciol., 39(133), 463-470.

Harrison, W.D., K.A. Echelmeyer and C.F. Larsen. 1998. Measurement of temperature in a margin of Ice Stream B, Antarctica: implications for margin migration and lateral drag. J. Glaciol., 44(148), 615-624.

Hawley, R.L., E.D. Waddington, G.W. Lamorey and K.C. Taylor. 2004. Vertical-strain measurements in firn at Siple Dome, Antarctica. J. Glaciol., 50(170), 447-452. 
Hughes, T. 1973. Is the West Antarctic ice sheet disintegrating? J. Geophys. Res., 78(33), 7884-7910.

Jezek, K.C. and RAMP Product Team. 2002. RAMP AMM-1 SAR image mosaic of Antarctica. Fairbanks, AK, Alaska SAR Facility, in association with the National Snow and Ice Data Center, Boulder, CO. (http://nsidc.org/data/docs/daac/nsidc0103_ ramp_mosaic.gd.html.)

Kamb, B. 2001. Basal zone of the West Antarctic ice streams and its role in lubrication of their rapid motion. In Alley, R.B. and R.A. Bindschadler, eds. The West Antarctic ice sheet: behavior and environment. Washington, DC, American Geophysical Union, 157-199. (Antarctic Research Series 77.)

Lamorey, G. 2003. Siple shallow core density metadata. Boulder CO, National Snow and Ice Data Center. (Digital media.)

Nereson, N.A., E.D. Waddington, C.F. Raymond and H.P. Jacobson. 1996. Predicted age-depth scales for Siple Dome and inland WAIS ice cores in West Antarctica. Geophys. Res. Lett., 23(22), 3163-3166.

Nereson, N.A., C.F. Raymond, E.D. Waddington and R.W. Jacobel. 1998. Migration of the Siple Dome ice divide, West Antarctica. J. Glaciol., 44(148), 643-652.

Nereson, N.A., C.F. Raymond, R.W. Jacobel and E.D. Waddington. 2000. The accumulation pattern across Siple Dome, West
Antarctica, inferred from radar-detected internal layers. J. Glaciol., 46(152), 75-87.

Pettit, E.C. 2003. Unique dynamic behaviours of ice divides: Siple Dome and the rheological properties of ice. (PhD thesis, University of Washington.)

Pettit, E.C. and E.D. Waddington. 2003. Ice flow at low deviatoric stress. J. Glaciol., 49(166), 359-369.

Raymond, C.F. 1983. Deformation in the vicinity of ice divides. J. Glaciol., 29(103), 357-373.

Raymond, C.F., N.A. Nereson, A.M. Gades, H. Conway, R. Jacobel and T. Scambos. 1995. Geometry and stratigraphy of Siple Dome, Antarctica. Antarct. J. U.S., 30(5), Review 1995, 91-93.

Rose, K.E. 1979. Characteristics of ice flow in Marie Byrd Land, Antarctica. J. Glaciol., 24(90), 63-75.

Taylor, K.C. and 13 others. 2003. Dating of SDM-A; O-514: Nov. 2003. Boulder, CO, National Snow and Ice Data Center. (Digital media.)

Zumberge, J.H., B.M.E. Smith and A. Fuzesy. 1969. Ross Ice Shelf studies, 1969. Antarct. J. U.S., 4(5), 215-216.

Zumberge, M.A. and 6 others. 2002. Measurement of vertical strain and velocity at Siple Dome, Antarctica, with optical sensors. J. Glaciol., 48(161), 217-225. 